\title{
POSTPRINT
}

\section{Resolving complex anaphors}

\section{Evidence from online comprehension}

Konstanze Marx, Ina Bornkessel-Schlesewsky and Matthias Schlesewsky

This study investigates the question of whether the processing of complex anaphors require more cognitive effort than the processing of NP-anaphors. Complex anaphors refer to abstract objects which are not introduced as a noun phrase and bring about the creation of a new discourse referent. This creation is called "complexation process" (see also Consten et al. this volume). We describe ERP findings which provide converging support for the assumption that the cognitive cost of this complexation process is higher than the cognitive cost of processing NP-anaphors.

\section{Introduction}

In this study, we distinguish two kinds of anaphors, direct noun phrase anaphors (NP-anaphors) and complex anaphors. This distinction is based on two differences. First, NP-anaphors characteristically refer back to concrete referents (Cornish 1986, Schwarz 2000) whereas complex-anaphors (see Schwarz 2000, SchwarzFriesel et al. 2004) ${ }^{1}$ refer to abstract objects (such as propositions, facts and events). Second, NP-anaphors refer to an entity that has already been introduced in the text by a noun phrase (NP), while complex anaphors refer to sentences or larger text segments and at the same time introduce a referent for them into the discourse representation. For instance, the discourse referent which das Auto in sen-

1. Researchers use different terms to refer to the phenomenon, e.g. "abstract object anaphora" (Asher 1993), "labelling" (Francis 1994) or "shell nouns" (Schmid 2000). 
tence (1) refers to is already established in the mental discourse representation ${ }^{2}$ (Schwarz 2001), but the first sentence in example (2) does not provide a discourse referent for the accident, its creation is due to the complex anaphor der Unfall.

(1) Der BMW fuhr gegen einen Baum. Das Auto hatte einen Totalschaden. The BMW crashed into a tree. The car got totally damaged.

(2) Der BMW fuhr gegen einen Baum. Der Unfall kostete glücklicherweise keinen das Leben. The BMW crashed into a tree. Fortunately there were no casualities in this accident.

Anaphors are important coherence markers in a text since they can keep a referent activated in a mental discourse representation. Once a referent has been introduced further expressions can refer to it.

This process works reasonably well as long as these referents are entities introduced by noun phrases. But how does the resolution of the anaphoric relation work if there is no such NP-referent available? We assume that abstract discourse referents are only established in a mental discourse representation once there is a complex-anaphoric expression that motivates and initiates this process. Intuitively, we would expect that this so-called complexation process (see also Consten et al. in this volume) calls for a greater cognitive effort. This greater cognitive effort can be put down to the fact that in the case of complex anaphors, a new referent must be established, whereas in the case of NP-anaphors an already existing referent is reactivated. We have conducted an event related brain potential (ERP) experiment to find out whether this prediction is borne out. Does the complexation process show up as a physiological effect?

Before we introduce our study we will briefly sketch the ERP method in general and review some relevant previous ERP findings.

\section{Methodological prerequisites}

Event-related potentials (ERPs) reflect electrical brain activity which takes place before, during or after a sensoric, motoric or psychological event in the electroencephalogram (EEG) (see Frisch 2000, Hahne 1997, Kutas et al. for further informa-

2. The mental discourse representation is often referred to with the term mental model, since there is no common opinion over the characteristics and we cannot review the whole debate, we used the more general term mental discourse representation which includes "all participating referents, their mutual relations as well as the events and situations in which these referents are engaged" (Schwarz 2001, 18). The mental representation generates on the basis of textual and knowledge information. 
tion). They make it possible to investigate the brain's reaction to a specific linguistic stimulus. ERPs are measured over electrodes which are placed on the scalp. They have a lower amplitude extension than the basic EEG-activity and have to be extracted by averaging over many time periods which include the interesting event.

The method can be used for the investigation of several steps in the text comprehension process (see among others Fischler 1990), ERPs can be recorded immediately during the visual and acoustic presentation of linguistic material and make possible a non-invasive online observation of neuronal processes during language processing.

Another advantage of the ERP-method is that participants need not carry out additional tasks (see Garnsey 1993 for an overview). ${ }^{3}$

ERPs are relative measures, i.e., a critical condition must always be evaluated with reference to a control condition. The values for a negativity or positivity cannot be interpreted in isolation. ERPs are characterized by specific components which are language sensitive. The question of how these components should be defined is still under debate (see Coles and Rugg 1995). Based on the classical definition of Donchin et al. (1978) components are characterized by four features:

- polarity Are there positive or negative peaks in the recorded waveforms?

- latency How long is the time period between the presentation of a critical stimulus and the amplitude maximum ? $^{4}$

- topography At which electrode positions can a maximum deviation be observed? ${ }^{5}$

- sensitivity How susceptible is an effect to experimental manipulations?

Important for language processing are components such as (E) $\mathrm{LAN}^{6}$ and $\mathrm{P} 600$, which have often been associated with syntactic processing and N400, which mainly correlates with lexical-semantic manipulations. (For problems with such oneto-one association between components and linguistic domains see Bornkessel et al. 2004 and Roehm et al. 2004.) As indicated by the names for these components,

3. To make sure that subjects are attending to the stimuli additional tasks are used in practice nevertheless.

4. "As a rule of thumb, differences in wave shape and/ or scalp distribution between two or more conditions are interpreted as reflecting the activity of distinct neuronal populations subserving qualitatively different processes, whereas differences in amplitude and/ or latency are interpreted as modulations in the activity of the same or related neuronal populations subserving processes that differ quantitatively" (Kutas 1993).

5. But associations between activity at a certain electrode and the directly underlying brain region are not allowed (see Streb 2000, Friederici 2003).

6. This is an abbreviation for "(early) left anterior negativity". 
N400 is a negative peak latency $400 \mathrm{msec}$ after its eliciting event, and P600, a positive peak latency after $600 \mathrm{msec}$.

\section{Relevant previous ERP findings}

As just mentioned, the N400 is often correlated with semantic processing whereas the P600 often reflects syntactic processes. The following paragraph shows that both components are sensible to anaphoric processing, which might suggest that it combines syntactic and semantic processing.

Streb (2000) manipulated the difficulty of integrating an anaphoric expression into a mental discourse representation by varying the detection difficulty of the antecedent: She varies the textual distance between anaphor and antecedent in a first experiment, the syntactic positions of antecedent and anaphor in a second experiment and the anaphoric expression itself in both experiments.

Her test items in the first experiment consisted of three related context sentences, a target sentence including an anaphoric reference to one of these characters, and a closing yes/no-question. The anaphor referred back to sentences 1, 2, and 3 equally often ( 3 ).

(3) context:

sl: Lisa schlendert über einen Basar. Lisa strolls across a bazaar.

s2: Peter verkauft Edelsteine an Touristen. Peter sells gems to tourists.

s3: Die Steine sind hervorragend geschliffen. The gems are cut excellently.

Target: Nun wird Lisa/sie dem Händler einen Diamanten abkaufen. Then Lisa/ she will buy a diamond from the trader.

Question: Kauft Lisa den Diamanten? Does Lisa buy the diamond?

Streb (2000) found that comprehension times increased with the distance between anaphor and antecedent. The ERP findings reveal a relatively larger $\mathrm{N} 400$ (for pronouns and proper names) for the far and the medium distance condition in comparison to the near distance condition.

Streb (2000) (see also Streb et al. 2004) attributes this effect to semantic integration processes that are increasingly demanding (in relation to the increasing distance between anaphor and antecedent).

The second experiment investigated whether the anaphoric processing depends on parallel (4) and non-parallel (5) sentence structures.

(4) Peter besucht Julia in der Klinik. Dort hat Peter dem Arzt eine Frage gestellt. Peter visits Julia in the hospital. There Peter asked the doctor a question. (Streb 2000, 69) 
(5) Peter besucht Julia in der Klinik. Dort hat die Schwester Peter das Zimmer gezeigt. Peter visits Julia in the hospital. There the nurse shows $\underline{\text { Peter the room. }}$ (Streb 2000, 69)

The first finding was that comprehension questions following non-parallel structures are answered more slowly. More important was the observed negative peak latency for non-parallel structures in a time window from 510 to $600 \mathrm{msec}$ after the critical stimulus. This modulation of the $\mathrm{N} 400$ effect reflects the more demanding integration of a less expected antecedent in a mental discourse representation.

Kulik et al. (2004) compared hyperonymic with repeated anaphoric expressions. They also varied the syntactic position of the anaphoric expression.

(6) neutral context: Peter fragt sich, was in dem Garten passiert war. Peter wonders what had happened in the garden.

(7) non-neutral context: Peter fragt sich, wer in dem Garten den Karpfen gestohlen hat. Peter wonders who had stolen the carp in the garden.

(8) Target ( $\arg 1)$ : Dann erfuhr er, dass den Karpfen/ Fisch der Junge gestohlen hat. Then he was told that the carp/ the fish had been stolen by the boy.

(9) Target (arg2): Dann erfuhr er, dass der Junge den Karpfen/ Fisch gestohlen hat. Then he was told that the boy had stolen the carp/ the fish.

Kulik et al. (2004) found no differences between Karpfen vs. Fisch as long as the target sentences (8) and (9) were introduced in a neutral manner (6). Significant differences between hyperonymic and repeated anaphoric expressions were observed in combination with (7). Both show a reduced N400 in comparison with the same word in a neutral context, but the reduction for hyperonymic expressions sets in with a delay of $70 \mathrm{msec}$ in comparison to that for repeated expressions. While the reduction for the repetition of Karpfen shows up in a time window from 300 to $500 \mathrm{msec}$, the effect for the anaphoric hyperonym Fisch was observed in a time window from 370 to $570 \mathrm{msec}$.

The authors interpret their findings as evidence for the hypothesis that semantic relations facilitate the establishing of a coreference relation. The results indicate how long it might take to resolve a hyperonym-hyponym relation.

The N400-effect in the above mentioned studies leads to the conclusion that this component might indicate the cognitive effort for the anaphor resolution process. The more difficult the search for an antecedent is, the higher the negative peak of the waveform (Streb 2000) seems to be. The results of Kulik et al. (2004) tie in with these findings. They observed a reduction of the $\mathrm{N} 400$ as soon as the anaphor processing was facilitated by lexical repetition or a semantic relation between antecedent and anaphoric expression. 
Burkhardt (2005) investigated how bridging relations (indirect anaphors, see Schwarz 2000) are encoded in the mental discourse representation. She compared three conditions: direct anaphors (lexical repetition) (a), indirect anaphors (b), no anaphoric relation (c), see (10).

(10) context a): Regine beschreibt einen Portier aus dem Adlon. Regine describes a doorman from the Adlon.

context b): Rebekka beschreibt ein Hotel in der Eifel. Rebekka describes a hotel in the Eifel.

context c): Ruth schwatzt gelegentlich mit ihrer Friseurin. Ruth chats occasionally with her hairdresser.

Target: Sie denkt, dass der Portier wohl überqualifiziert war. She thinks that the doorman was probably overqualified. (Burkhardt 2005, 75)

The definite noun phrase (without any anaphoric relation) in context c) elicited a N400 and a P600 effect. As expected (see among others Kulik et al. 2004) the anaphor in context a) elicited a reduced N400. The indirect anaphoric expression in context b) elicited also a reduced N400 but additionally a P600 (left posterior) as seen in context $\mathrm{c}$ ).

Indirect anaphors seem to be processed on the basis of two different patterns (Burkhardt 2005). On the one hand the resolution is comparable with the resolution of direct anaphors which refer to already known (and established) referents (reduction of the N400), on the other hand the resolution is comparable with new entities which do not yet have a slot in the mental discourse representation and need to be established in a process which demands cognitive effort (P600).

These studies show that the $\mathrm{N} 400$ as well as the P600 component might be interpreted as indicators for cognitive effort during the anaphoric processing.

\section{ERP Study}

\subsection{Participants}

25 undergraduate students ( 12 female) of the University of Leipzig and one unemployed woman between 20 and 29 years of age (mean age 24.9) participated in the study. All were right-handed native speakers of German with normal or correctedto-normal visual acuity. They were paid for their participation. 


\subsection{Stimuli}

In order to find out whether the understanding of complex anaphorical relations makes a difference in comparison to noun phrase anaphorical relations four minitexts consisting of two sentences each were constructed. The conditions were

Cond 1 NP-anaphorical expression (definite)(11)

Cond 2 complex-anaphorical expression (definite) (12)

Cond 3 critical item of cond 1 neutrally introduced' (indefinite) (13)

Cond 4 critical item of cond 2 neutrally introduced (indefinite) (14)

The first two conditions started with identical first sentences, but the second sentences started either with a concrete (NP anaphor) or an abstract noun (complex anaphor). The experimental items were exactly these nouns, so it was not necessary to continue the sentences in the same way. In that manner it was possible to construct meaningful text passages.

Nevertheless, we used the same syntactical parallel pattern for condition one and two as well as for conditions three and four. The text passages for the first two conditions start always with obwohl (although), the text passages for the last two conditions begin with als (when).

(11) Obwohl die Titanic als unsinkbar galt, ging sie unter. Dieses Schiff war ein fahrendes Luxushotel. Although the Titanic was said to be unsinkable, it went down. This ship was a swimming luxury hotel.

(12) Obwohl die Titanic als unsinkbar galt, ging sie unter. Dieses Unglück wurde sogar verfilmt. Although the Titanic was said to be unsinkable, it went down. This accident was even filmed.

For each such pair of conditions, two additional text passages were constructed in which the critical lexemes (in 11, ship and in 12, accident) were introduced in a neutral and indefinite manner. On the one hand, this allowed us to record the data of "plain" concrete and abstract nouns. On the other hand, these conditions were necessary in order to make sure that semantic relations between the referential and the anaphoric expression do not falsify the data (see Kulik et al. 2004).

(13) Als Hanna ins Ferienhaus kam, öffnete sie die Fenster weit. Ein Schiff war am Horizont $\mathrm{zu}$ sehen. When Hanna entered the holiday house, she opened the windows wide. A ship could be seen on the horizon.

7. "Neutral" means that there was neither an anaphorical nor a conceptual relation between the two sentences. 
(14) Als Marcel aus dem Büro kam, gab es eine Menschenansammlung. Ein Unglück war passiert. When Marcel left his office, there was a crowd. An accident had happened.

60 blocks consisting of four conditions each were constructed altogether. In addition, we prepared 30 filler items which were totally senseless and without any logical context. ${ }^{8}$

\subsection{Norming study}

Methods and Materials All items were tested via a questionnaire in order to choose the best candidates for the ERP study. There were four versions of the questionnaires in order to make sure that each person would only read one condition of a particular block. Subjects had to judge the acceptability of text passages on a seven-stage scale (one meant "absolutely acceptable" while seven meant "completely unacceptable").

Participants 48 undergraduate students ( 34 female) of the University of Jena between 19 and 30 years of age (mean age: 22.5) participated in the norming study. It took the students approximately 15 minutes to fill out the questionnaires. The participants did not receive any payment. ${ }^{9}$

Results and data selection All conditions with a mean higher than 3 were excluded. In a next step we calculated the differences between the means of the conditions that made up one block. Whenever the difference exceeded one, we discarded that specific block. In that manner 40 blocks for the final experimental sessions were selected. The filler passages could be used without exception (mean: 6.24), they also served as a model for 50 additionally constructed filler passages.

In the end 40 blocks consisting of four conditions each and 80 unacceptable filler items, altogether 240 test passages, were tested. By randomizing two lists were created with different orders to avoid any processing effect that would be

8. a) Obwohl es gesund ist, isst Maria Haferflocken. Diese Frau sitzt im Schuh. Although they are healthy, Mary eats rolled oats. This woman is sitting in a shoe.

b) Obwohl das Paar tanzte, bewegte es sich. Dieser Gedanke schimpfte über den Flur. Although the couple was dancing, they moved. This thought grumbled trough the hallway.

c) Als die Sonne schien, war es dunkel. Ein Leopard hielt einen Vortrag. When the sun was shining, it was dark. A leopard was giving a lecture.

d) Als Patrick in eine neue Stadt zog, hatte er keine neue Adresse. Ein Rat diskutierte im Plattenladen. When Patrick moved to another town he did not have a new postal address. Discussed in a record store.

9. We are grateful to Prof. Dr. Monika Schwarz-Friesel and Prof. Dr. Evyatar Friesel who allowed us to conduct this survey during their lectures. 
caused by the particular order of the stimuli items. The lists were subdivided into six presentation blocks of 40 trials each.

\subsection{ERP Recording}

EEG data were collected from $64 \mathrm{Ag} / \mathrm{AgCl}$ scalp electrodes mounted in a standard electrode cap (Elektro Cap International), a system that adheres to the standard international 10-20 system for electrode positioning of the American Electroencephalographic Society. ${ }^{10}$

Artefacts that result from ocular movement must be detected and discarded prior to data analysis. To this end, vertical and horizontal eye movements and blinks were monitored by means of two sets of additional electrode pairs, which were placed above and below the left eye (EOGV) and at the outer canthi of the left and right eye (EOGH).

\subsection{Procedure}

The passages were presented visually. Subjects were instructed to read the text passages carefully and to decide whether the texts made sense and were correct German texts. The texts did not have to be true (see 15).

(15) Matthäus wird neuer Bundestrainer. Der frühere Nationalspieler hat einen Vertrag bis 2007 unterschrieben. Matthäus is going to be the new coach of the German national soccer team. The former national soccer player has signed a contract till 2007.

As a second task they were confronted with a single word and had to decide whether this word had been presented in the previous text or not. The minitexts (consisting of two sentences) were presented segmentally. These tasks were used to make sure that subjects were attending to the minitexts and to examine how acceptable participants would judge the passages to be under critical experimental conditions.

Furthermore the subjects were asked not to move or blink during the presentation time of the texts. They were allowed to blink during the verification tasks and between the blocks, where they were given short breaks.

After reading the instructions the subjects were prepared for the experimental session (application of the electrodes). The resistance of the electrodes was kept below $5 \mathrm{KOhm}$.

10. ERPs were recorded from the following positions: FP1, FPZ, FP2, AF7, AF3, AFZ, AF4, AF8, F9, F7, F5, F3, FZ, F4, F6, F8, F10, FT9, FT7, FC5, FC3, FCZ, FC4, FC6, FT8, FT10, T9, T7, C5, C3, CZ, C4, C6, T8, A2, TP9, TP7, CP5, CP3, CPZ, CP4, CP6, TP8, TP10, P9, P7, P5, P3, PZ, $\mathrm{P} 4, \mathrm{P} 6, \mathrm{P} 8, \mathrm{P} 10, \mathrm{PO} 7, \mathrm{PO} 3, \mathrm{POZ}, \mathrm{PO} 4, \mathrm{PO} 8, \mathrm{O} 1, \mathrm{OZ}$ and $\mathrm{O} 2$. ERP data were referenced to the left mastoid. $\mathrm{C} 2$ served as ground. 
A practice session helped the subjects to get used to the modalities. It consisted of twelve minitexts, four of which were not acceptable. The text passages were presented in six blocks of 40 passages each ( 80 passages were not acceptable). One block lasted about ten minutes. At the beginning of each text passage, a fixation star appeared in the centre of the screen for $300 \mathrm{msecs}$. Each segment was presented for $400 \mathrm{msecs}$ (segments longer than eight letters appeared for $500 \mathrm{msecs}$ ). The breaks between each presented segment lasted 100 msecs.

There was an interval of $500 \mathrm{msecs}$ between the last word of the first sentence and the first word of the second sentence. 500 msecs after the last word of the second sentence three question marks appeared on the screen. They indicated that the subject should decide whether the minitext was an acceptable German utterance. 500 msecs after the subject's reaction or 2000 msecs after the question marks had appeared (in case the subject did not answer) the verification word showed up for $2000 \mathrm{msecs}$ maximum. The next stimulus item was presented a total of $1000 \mathrm{msecs}$ after the verification task.

The entire session lasted approximately 150 to 180 minutes, including electrode application and removal.

\subsection{Results}

Data of three subjects (two of them male) had to be excluded from the final analysis due to extensive EEG recording artefacts. Therefore the results were based on 23 subjects.

\subsubsection{Behavioural Data}

Reaction time in msec and percentage of errors are presented in table $1 .{ }^{11}$

\begin{tabular}{lcccc}
\hline & RT T1 & RT T2 & Er T1 & Er T2 \\
\hline cond 1 & 363 & 806 & .77 & 6.25 \\
cond 2 & 359 & 789 & 1.35 & 3.37 \\
cond 3 & 411 & 760 & 1.73 & 6.92 \\
cond 4 & 364 & 802 & 1.06 & 8.65 \\
FI & 352 & 815 & 2.88 & 7.12 \\
\hline
\end{tabular}

Figure 1. Behavioural data: Critical item by condition

11. cond $1=\mathrm{NP}$-anaphor (introduced as definite concrete noun), cond $2=$ complex-anaphor (introduced as definite abstract noun), cond 3 = indefinitely introduced concrete noun, cond 4 $=$ indefinitely introduced abstract noun, $\mathrm{FI}=$ filler passages (unacceptable);

$\mathrm{RT} \mathrm{T} 1=$ mean reaction time probe detection task, $\mathrm{RT} \mathrm{T} 2=$ reaction time lexical recognition task, $\mathrm{Er} \mathrm{T} 1=$ mean errors in probe detection task, $\mathrm{Er} \mathrm{T} 2=$ mean errors in lexical recognition task. 
There is no significant difference in the error or reaction times. The acceptability of all items was high. It took the participants approximately $50 \mathrm{msec}$ longer to come up with a decision only when it came to decide whether a sentence introduced by an indefinite concrete noun (condition 3 ) was acceptable.

Only experimental items that elicited a correct response to the probe detection task as well as to the lexical recognition task were included in the data analysis.

To conclude, behavioural data showed general attention, items that were answered incorrectly were discarded from the final analysis.

\subsubsection{ERP data}

Figure 2 displays the grand average event-related brain potentials for all conditions. The most striking effect is a large negative deflection emerging around $400 \mathrm{msec}$ after the critical stimulus (indefinite introduction of concrete noun) in condition 3 (dotted line).

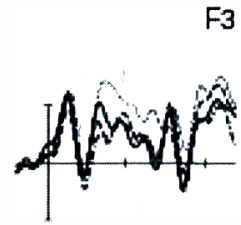

C3

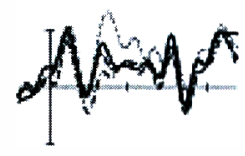

P3
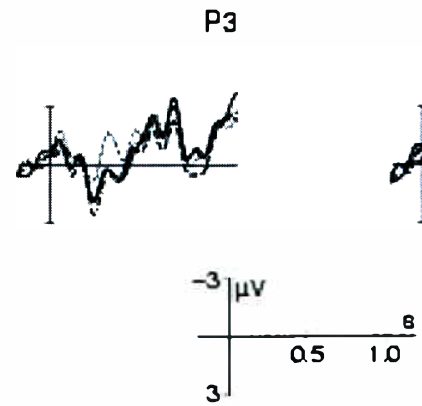

FZ

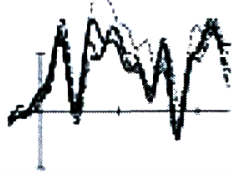

CZ

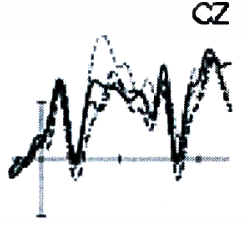

PZ

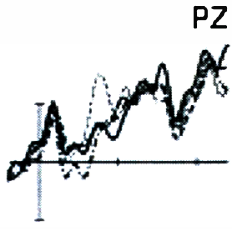

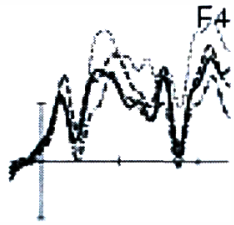

$\mathrm{C}_{4}$

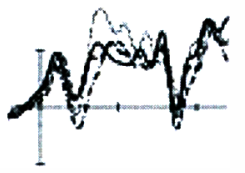

P4

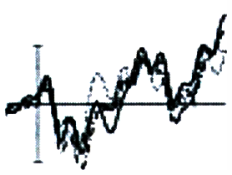

- NP-anaphor (cond 1) ( $n=23)$

-... indefinite concrete item (cond 3$)(n=23)$

-.. complex anaphor (cond 2) ( $n=23)$

-.-- indefinite abstract item (cond 4$)(n=23)$

Figure 2. Grand average ERPs of all conditions 
The grand average ERP waveforms for NP anaphoric expressions (condition 1) and complex anaphoric expressions (condition 2) are illustrated in figure 3. The two conditions do not appear to differ from one another.

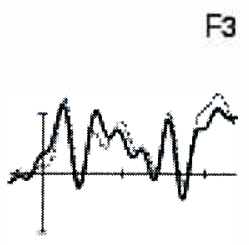

$\mathrm{C} 3$

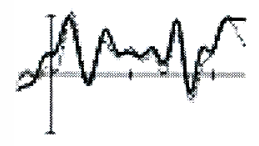

$\mathrm{P3}$
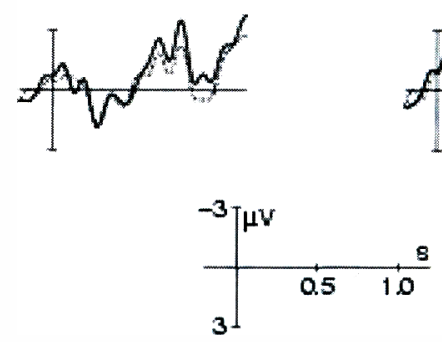

FZ

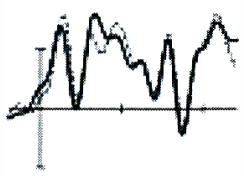

$\mathrm{CZ}$

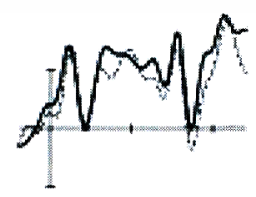

$\mathrm{PZ}$

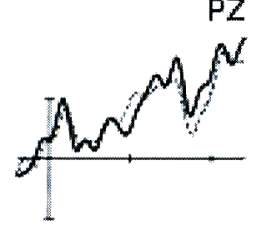

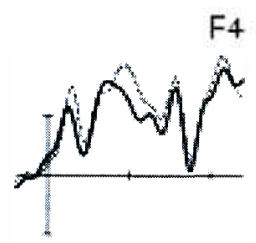

$\mathrm{C} 4$

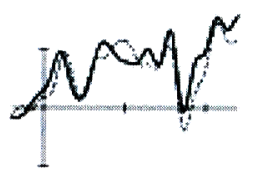

$\mathrm{P} 4$

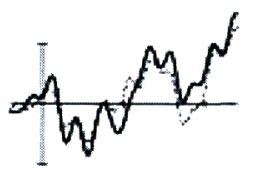

- NP anaphoric expression $(n=23)$ complex anaphoric expression $(n=23)$

Figure 3. Grand average ERPs elicited by the NP anaphoric expression and the complex anaphoric expression

The statistical significance of the concreteness effect was assessed by repeated measures ANOVA. The factors were concreteness (abstract vs. concrete nouns) and definiteness (definite vs. indefinite nouns). From the perspective of this factorisation, the critical complex anaphor condition was defined as abstract-definite.

The statistical analysis showed a significant main effect of concreteness ( $F$ $(1,22)=18.37, \mathrm{p}<0.001)$ and a significant interaction between concreteness and definiteness $(\mathrm{F}(1,22)=6.34, \mathrm{p}<0.02)$. This interaction indicates that definiteness modulates the processing of the distinction between concrete and abstract nouns. To examine this point further, we compared the differences between concrete and abstract nouns for each of the levels of the factor definiteness (i.e., separately for definite and indefinite nouns). These planned comparisons revealed a significant 
effect of concreteness for indefinite nouns $(F(1,22)=17.51, \mathrm{p}<0.001)$, but no significant difference between concrete and abstract definite nouns.

\subsection{Discussion}

In principle there are two results:

- N400 effect for indefinite introduced (non-anaphoric) concrete nouns

- no effect for complex anaphors

\begin{tabular}{lll}
\hline Variable & \multicolumn{1}{c}{ concrete } & \multicolumn{1}{c}{ abstract } \\
\hline Definite & no effect NP-anaphor & no effect complex anaphor \\
Indefinite & significant $N 400$ & no effect condition 4 \\
\hline
\end{tabular}

Figure 4. Overview ERP findings

The main effect found in this experiment is a concreteness effect. Concrete nouns (introduced as indefinite NPs) show a significant N400-effect, abstract nouns (introduced as indefinite NPs) do not. These results are in line with previous studies showing increased $\mathrm{N} 400$ amplitudes for concrete vs. abstract nouns (Holcomb et al. 1999). But this concreteness effect interacts with definiteness in that the way in which concrete nouns are "anchored" within the discourse is crucial.

More importantly, the postulated complexation process did not reflect a neurophysiological correlate. There are three potential explanations for this phenomenon:

1. There is no anaphorical complexation process (a complex discourse entity is already established by the antecedent).

2. There is an anaphorical complexation process, but it has no measurable physiological correlate.

3. There is an anaphorical complexation process and it has a physiological correlate, but the correlative cannot be found by this experiment design.

The last explanation seems to be the most promising. Since previous work (Schwarz 2000 , Consten et al. in this volume) has shown that complex anaphors can motivate the process of establishing a new referent, explanation 1 appears unlikely.

While explanation 2 cannot be excluded unequivocally, a number of studies have shown that the ERP method is sensitive to anaphoric processing (see section 3). In particular, as argued by Burkhardt (2005), the establishment of a new referent can be associated with ERP activity. One would therefore have to conclude that the absence of a measurable electrophysiological effect for complex anaphors is a specific property of this particular anaphoric phenomenon. 
Turning now to explanation 3, this type of situation could have arisen on account of the following factors:

1. demonstrative noun phrases where pronouns are most likely (cond 1)

2. variability of semantic relations (cond 1)

3. subject-object variability (cond 1 )

4. different degrees of resolving difficulty (cond 2)

1. One striking difficulty in constructing the test items had to do with the fact that complex anaphors usually take the form of demonstrative noun phrases. In order to create a basis for comparison, NP-anaphors had to be demonstrative noun phrases as well, which forced us to use such demonstrative NPs in the test items of condition 1 in positions where readers would expect a pronoun. But this strategy calls for a careful design of test items in order to not to bring in the so-called "disjoint reading effect" (ARIEL 2001): Full NP anaphors which refer to referents of high accessibility make readers add a referent to the mental discourse representation instead of recognizing the intended coreference. Thus we had to rule out that the test items in condition 1 might motivate the readers to activate a new referent before they realised that they only had to reactivate an already introduced referent. This would involve additional cognitive effort, since condition 1 would not be as easy to resolve as needed for the compatibility of both processes.

We tried to fence off the disjoint reading effect in two ways: First, we constructed test items which started off with a subordinate clause and thus sounded more natural. Second, we used the norming study (see section 4.3) in order to ensure a high degree of acceptability. However, the results of our study might point to the fact that these attempts were not completely successful in ruling out the disjoint reading effect.

2. In condition 1 the semantic relations between antecedent and anaphoric expressions changed from time to time. While there are no indications yet that different semantic relations might affect the degree of resolution difficulty, this variability might nevertheless have made resolution more difficult.

3. We also need to take into account the syntactic role of the antecedent. Equal shares of NP anaphors in condition 1 referred to the subject and to the object of the preceding sentence. When analysing the data in a first step we did not distinguish these two groups. But there are hints in the literature which suggest differences in anaphora resolution depending on whether the anaphoric expression refers to the object or to the subject of the preceding sentence in that anaphoric expressions referring to the subject are resolved more easily (Wykes 1981, Corbett and Chang 1983, Müsseler and Rickheit 1990). Our extended analysis incorporates this idea (4.8). 
4. The complex anaphoric expressions in condition 2 referred to states of affairs, events, processes as well as to facts or propositions (see Consten and Marx 2006). There might be differences concerning the cognitive effort and strategies involved in resolving these different types of complex anaphors. We could not integrate these considerations in the present study. An experiment focussing on this question is in progress.

\subsection{Extended ERP analysis}

In the extended analysis, we investigated the question of whether a difference between the processing of NP anaphors in comparison to complex-anaphors might become obvious as soon as test items from condition 1 were separated according to the syntactic function of antecedents (see Wykes 1981, Corbett and Chang 1983).

\section{Material}

We separated the material into two groups depending on whether the NP-anaphor in condition 1 referred to the subject or to the object of the preceding sentence and focussed on the resulting grand averages.

\section{Results: ERP data}

Figure 5 shows the curves which resulted from the grand averages when reading condition 1 (antecedent $=$ subject) and condition 2 (complex anaphor). For condition 2 a late positivity (P600) can be recognised. As figure 6 shows, there is no such effect when complex anaphoric processing is compared to NP anaphors which relate to the object of the preceding sentence.

The statistical analysis showed no significant effect for one of the factors Region $^{12}$, Type of Anaphor ${ }^{13}$ or Type of Antecedent ${ }^{14}$ as long as all regions of interest were integrated in the ANOVA. This might be due to reduced statistical power because of the rearrangement of the considered data. Nevertheless, results from Burkhardt (2005) for indirect anaphors motivated a closer look on possible interactions between the factors mentioned above.

12. Where does the effect take place?

13. Which kind of anaphoric expression is used; concrete anaphoric expression referring to an NP in condition 1 or abstract anaphoric condition referring to a sentence in condition 2 ?

14. Does the anaphoric expression in condition 1 refer to the subject or the object of the prior sentence? 
$\mathrm{F} 3$

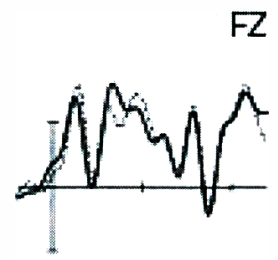

FZ

$\mathrm{F}_{4}$

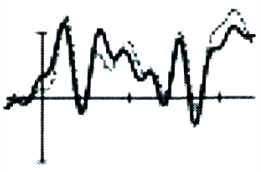

$\mathrm{C} 3$

$\mathrm{CZ}$

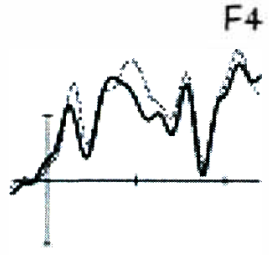

C4
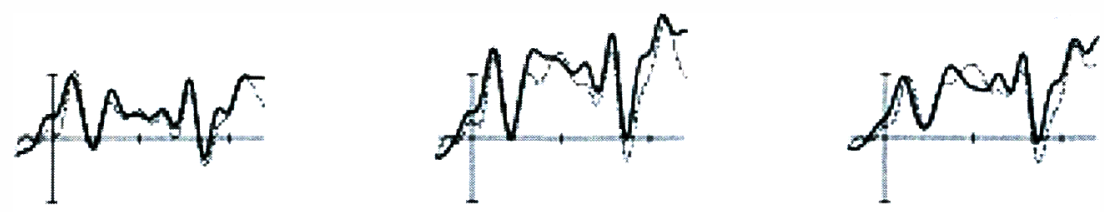

P3

$\mathrm{PZ}$

$\mathrm{P}_{4}$
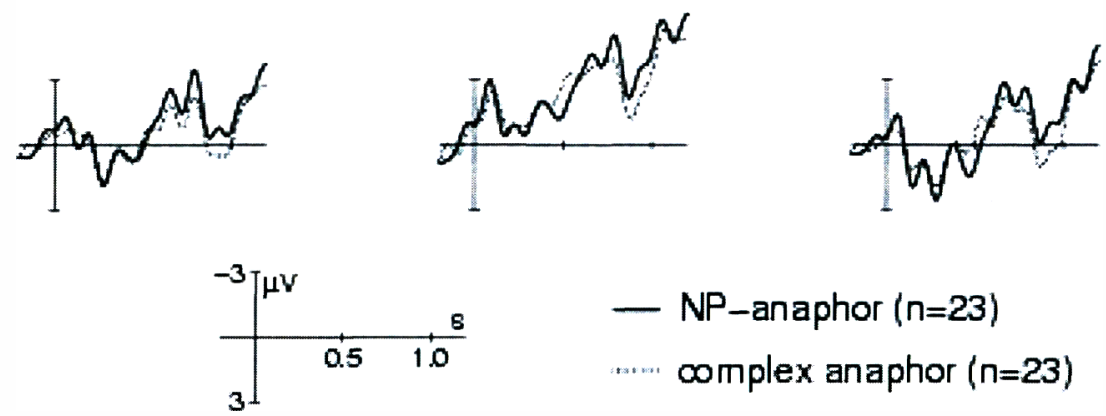

- NP-anaphor $(n=23)$

complex anaphor $(n=23)$

Figure 5. NP-anaphor vs. complex anaphor when antecedent for NP anaphor is subject

We found a marginal interaction between the factors Type of Anaphor and Type of Antecent in the right posterior region $(\mathrm{F}(1,22)=3,86, \mathrm{p}<0.07)$. Separate analyses for passages with subject vs. object antecedents showed a significant effect of concreteness in the Subject-Type $(\mathrm{F}(1,22)=4,69, \mathrm{p}<0.05)$, which was due to an increased positivity for abstract anaphorical expressions in condition 2 . There was no such difference when the anaphor referred to an object. 
F3
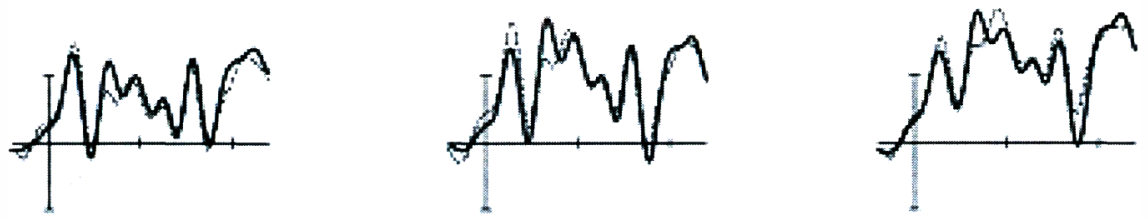

C3

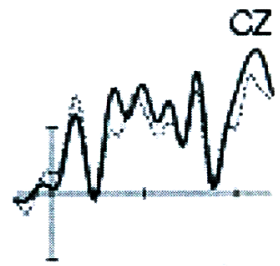

C4

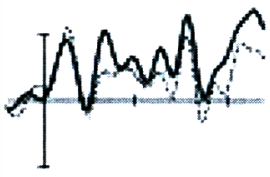

P3

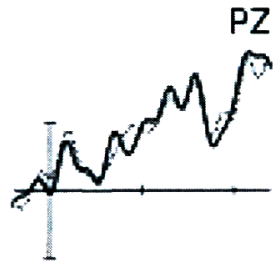

$\mathrm{P}_{4}$

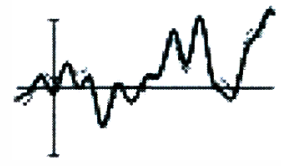

- NP-anaphor $(n=23)$
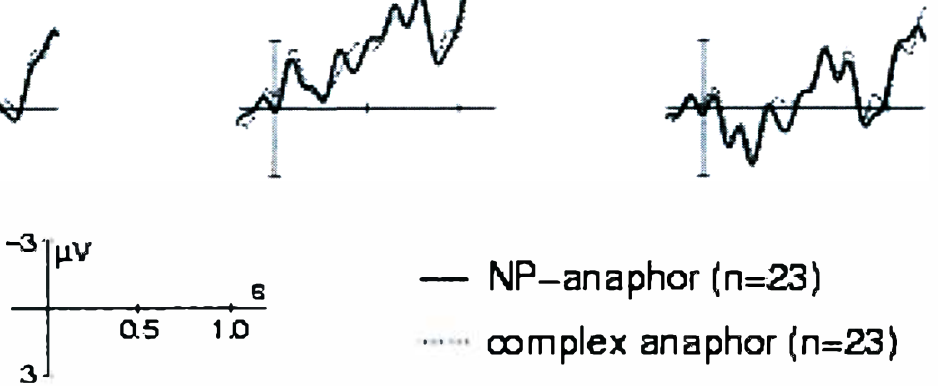

Figure 6. NP-anaphor vs. complex anaphor when antecedent for NP anaphor is object

\section{Discussion}

The reanalysis of the material corroborated the assumption that complex anaphoric processing and therefore the establishment of a new referent differentiates from $\mathrm{NP}$-anaphoric processing. Complex anaphors-in contrast to NP-anaphors referring to the subject of the preceding sentence-elicit a late positivity. This component was recently interpreted as indicator for cognitive effort while establishing a new referent in the mental discourse representation. Our findings are in line with the assumption that NP-anaphors which relate to the subject of the prior sentence are easier to resolve than NP-anaphors which relate to the object of the prior sentence. We did not find a difference between complex anaphoric processing and $\mathrm{NP}$-anaphor in the latter case. This might be due to the fact that the cognitive effort involved in resolving NP-anaphors which relate to object antecedents and the process of establishing a new discourse referent (complexation process) might involve similar neurophysiological processing correlates. 


\section{Conclusion}

Complex anaphors motivate the integration of a new abstract referent into the mental discourse representation. The present study investigated the question of whether this postulated complexation process shows up in ERP data. In order to find out whether the referent establishing process is reflected in a prominent ERP component, we compared complex anaphors with NP-anaphors. In a first analysis we did not find a significant effect, which might be due to the variability in our first condition. An extended reanalysis of our material for complex anaphors in contrast to NP-anaphors relating to the subject of the preceding sentence showed a late positivity. This provides converging support for the assumption that the cognitive cost of processing complex anaphors is higher than the cognitive cost of processing NP-anaphors, because the former calls for the establishment of a new referent in a mental discourse representation.

\section{Acknowledgements}

This experiment was conducted at the Max Planck Institute for Human Cognitive and Brain Sciences in Leipzig, Germany. Thanks to Ina Koch for her support during data acquisition.

\section{References}

Ariel, M. 2001. Accessibility theory: An overview. In Text Representation. Linguistic and psycholinguistic aspects, T. Sanders, J. Schilperoord and W. Spooren (eds), 13-35. Amsterdam: John Benjamins.

Asher, N. 1993. Reference to Abstract Objects in Discourse. Dordrecht: Kluwer.

Bornkessel, I., McElree, B., Schlesewsky, M. and Friederici, A. 2004. Multidimensional contributions to garden path strength: Dissociating phrase structure from case marking. Journal of Memory and Language 51: 495-522.

Burkhardt, P. 2005. Resolving bridging dependencies online: Evidence for given and new properties of bridged definite DPs. In Proceedings of Constraints in Discourse', June 3-5,.2005, Dortmund.

Coles, M. and Rugg, M. 1995. Event-related brain potentials: An introduction. In M. Rugg and M. Coles (eds), Electrophysiology of Mind: Event-related brain potentials and cognition, 1. New York NY: OUP.

Consten, M. and Marx, K. 2006. Komplex-Anaphern-Rezeption und textuelle Funktion. In Text - Verstehen. Grammatik und darüber hinaus, H. Blühdorn, E. Breindl, and U.H. Wassner (eds), 375-379. Berlin: Walter de Gruyter.

Corbett, A. and Chang, F. 1983. Pronoun disambiguating: Accessing potential antecedent. Memory \& Cognition 11: 283-294. 
Cornish, F. 1986. Anaphoric Relations in English and French-A Discourse Perspective. London: Croom Helm.

Donchin, E., Ritter, W. and McCallum, W. 1978. Cognitive psychophysiology: The endogenous components of the ERP. In Event-Related Brain Potentials in Man, E. Callaway, P. Tueting, and S. Koslow (eds), 349. New York NY: Academic Press.

Fischler, I. 1990. Comprehending language with event-related potentials. In Event-Related Brain Potentials: Basic issues and applications, J. Rohrbaugh, R. Parasuraman, and Johnson, R. Jr. (eds), 165-177. New York NY: OUP.

Francis, G. 1994. Labelling discourse: An aspect of nominal-group lexical cohesion. In Advances in Written Text Analysis, C. Malcom (ed.), 83-101. London: Routledge.

Friederici, A. 2003. Neurobiologische Grundlagen der Sprache. In Neuropsychologie, H.-O. Karnath and P. Thier (eds), 367-377. Berlin: Springer.

Frisch, S. 2000. Verb-Argument-Struktur, Kasus und thematische Interpretation beim Sprachverstehen. $\mathrm{PhD}$ dissertation, Universität Potsdam.

Garnsey, S. M. 1993. Event-related Brain Potentials in the Study of Language: An Introduction. Language and Cognitive Processes 8: 337-356.

Hahne, A. 1997. Charakteristika syntaktischer und semantischer Prozesse bei der auditiven Sprachverarbeitung. Leipzig: MPI Series.

Holcomb, P.,.Kounios, J., Anderson, J. and West, W. 1999. Dual-coding, context availability, and concreteness effects in sentence comprehension: an electrophysiological investigation. Journal of Experimental Psychology: Learning Memory and Cognition 25:721-742.

Kulik, S., Bornkessel, I. and Schlesewsky, M. 2004. The on-line establishment of hyperonymic anaphorical relations. Poster, 17. CUNY Conference on Human Sentence Processing. University of Maryland, College Park.

Kutas, M. 1993. In the company of other words: Electrophysiological evidence for single-word and sentence context effects. Language and Cognitive Processes 8: 533-572.

Kutas, M., Van Petten, C. and Kluender, R. 1994 Psycholinguistics electrified II. In Handbook of Psycholinguistics, M.A Gernsbacher (ed.). San Diego CA: Academic Press.

Müsseler, J. and Rickheit, G. 1990. Komplexbildung in der Textverarbeitung. Die kognitive Auflösung pluraler Pronomen. Zeitschrift für Psychologie 198: 69-81.

Roehm, D., Schlesewsky, M., Bornkessel, I., Frisch, S. and Haider, H. 2004. Fractionating language comprehension via frequency characteristics of the human EEG. NeuroReport 15: 409-412.

Schmid, H.-J. 2000. English Abstract Nouns as Conceptual Shells. From corpus to cognition. Berlin: Mouton de Gruyter.

Schwarz, M. 2000. Indirekte Anaphern in Texten. Studien zur domänengebundenen Referenz und Kohärenz im Deutschen. Tübingen: Niemeyer.

Schwarz, M. 2001. Establishing coherence in text. Conceptual continuity and text-world models. Logos and Language 2: 15-23.

Schwarz-Friesel, M., Consten, M. and Marx, K. 2004. Semantische und konzeptuelle Prozesse bei der Verarbeitung von Komplex-Anaphern. In Flexibilität und Stabilität, I. Pohl (ed.), 67-86. Frankfurt am Main: Peter Lang.

Streb, J. 2000. Hirnelektrische Korrelate der Verarbeitung anaphorischer Verweise. PhD dissertation, Universität Marburg.

Streb, J., Hennighausen, E. and Rösler, F. 2004. Different anaphoric expressions are investigated by event-related brain potentials. Journal of Psycholinguistic Research 33: 175-201.

Wykes, T. 1981. Inference and children's comprehension of pronouns. Journal of Experimental Child Psychology 32: 264-279. 